\title{
SELEÇÃO PARA A RESISTÊNCIA À FERRUGEM EM PROGÊNIES DAS CULTIVARES DE CAFÉ IPR 99 E IPR $107\left({ }^{(1)}\right.$
}

\author{
GUSTAVO HIROSHI SERA $\left(\left(^{2}\right)\right.$; TUMORU SERA $\left({ }^{2}\right)$; DHALTON SHIGUER ITO $\left({ }^{3,7}\right)$; \\ INÊS CRISTINA DE BATISTA FONSECA $\left({ }^{4}\right)$; FABIO SEIDI KANAYAMA $\left({ }^{5}\right)$; \\ LEANDRO DEL GROSSI ( $\left.{ }^{(}\right)$; LUCIANA HARUMI SHIGUEOKA $\left(^{(}\right)$
}

\begin{abstract}
RESUMO
As cultivares de café IPR 99 (“Sarchimor") e IPR 107 ('IAPAR 59' x 'Mundo Novo IAC 376-4') eram no passado resistentes à ferrugem (Hemileia vastatrix). Os objetivos deste estudo foram: a) Identificar progênies dessas duas cultivares com resistência à ferrugem; b) Identificar progênies com resistência incompleta; c) Verificar a eficiência dos cruzamentos testes na seleção dessas cultivares. A avaliação da resistência em campo foi realizada em cafeeiros adultos expostos à população local de raças presentes no IAPAR. Foram avaliados 23 cruzamentos testes com progênies $F_{3}$ de 'IPR 107' e 5 com progênies $F_{4}$ de 'IPR 99'. Além disso, foram avaliadas 11 progênies $F_{4}$ de 'IPR 107' e 5 progênies $F_{5}$ de 'IPR 99', provenientes de autofecundação. Várias progênies das cultivares IPR 99 e 107 apresentaram alta freqüência de plantas com resistência completa e são portadoras de mais genes de resistência não quebrados pelas raças de ferrugem. Progênies das cultivares IPR 99 e IPR 107 com a resistência quebrada apresentaram resistência incompleta à população local de raças. Cruzamentos testes foram eficientes na seleção de progênies de café com mais genes de resistência não quebrados.
\end{abstract}

Palavras-chave: Coffea, cruzamento teste, genes $\mathrm{S}_{\mathrm{H}^{\prime}}$ Hemileia vastatrix, resistência durável.

\section{ABSTRACT}

\section{SELECTION FOR RESISTANCE TO RUST IN PROGENIES OF COFFEE CULTIVARS IPR 99 AND IPR 107}

All plants of the coffee cultivars IPR 99 (“Sarchimor") and IPR 107 ('IAPAR 59' x 'Mundo Novo IAC 376-4') were resistant to rust (Hemileia vastatrix) in the past. Currently, susceptible plants were observed in the two cultivars due to the breakdown of resistance by new rust races. The aims of this study were: a) to identify coffee (Coffea arabica L.) progenies of the two cultivars with resistance to rust; b) to identify progenies with incomplete resistance; c) to investigate the efficiency of test-crosses for selection from these cultivars. Evaluation for field resistance was carried out in adult plants subjected to natural infection by the local leaf rust population at IAPAR. Twenty-three test-crosses with $\mathrm{F}_{3}$ progenies of 'IPR 107' and five with $\mathrm{F}_{4}$ progenies of 'IPR 99' were evaluated. Moreover, $11 \mathrm{~F}_{4}$ progenies of 'IPR 107' and five $F_{5}$ progenies of 'IPR 99' derived from self pollinations were evaluated. Several progenies of the IPR 99 and 107 cultivars presented high frequency of resistant plants and thus should carry additional $S_{H}$ genes not defeated by specific rust races found at IAPAR. However, susceptible progenies of 'IPR 99' and 'IPR 107' presented incomplete resistance to the local race population. Test-crosses were efficient for selecting coffee progenies more resistant to rust.

Key words: Coffea, durable resistance, Hemileia vastatrix, $\mathrm{S}_{\mathrm{H}}$ genes, test-cross.

(1) Recebido para publicação $1 .^{\circ}$ de julho de 2008 e aceito em 21 de janeiro de 2010.

(²) Instituto Agronômico do Paraná (IAPAR), Caixa Postal 481, 86001-970, Londrina (PR). E-mail: gustavosera@iapar.br

(3) Doutorando em Agronomia da Universidade Estadual de Londrina (UEL). E-mail: itods@uol.com.br

( $\left.{ }^{4}\right)$ Departamento de Agronomia, Universidade Estadual de Londrina. E-mail: inescbf@uel.br

(5) Mestre em Agronomia da UEL.

(6) Bolsista da SETI.

(7) Bolsista do CNPq. 
A ferrugem alaranjada, causada pelo fungo Hemileia vastatrix Berk. et Br., ainda é uma das principais doenças do café, pois causa grandes perdas na produção e qualidade.

A resistência à ferrugem dos cafeeiros vem sendo quebrada pelo surgimento de novas raças, o que dificulta a obtenção de cultivares com resistência completa e durável. Vários genes de resistência em um mesmo genótipo dificultam esta quebra de resistência.

Os fatores de resistência dos cafeeiros conhecidos são $\mathrm{S}_{\mathrm{H}} 1$ a S $\mathrm{H} 9$ (Rodrigues-Junior et al., 1975; BETTENCOURT, 1981), contrastando com os respectivos fatores de virulência v1 a v9, os quais estão presentes, sozinhos ou em combinações, em 45 raças identificadas no mundo (VÁrzea e Marques, 2005). Os genes $S_{H} 6, S_{H} 7, S_{H} 8$ e $S_{H} 9$ são do $C$. canephora, um dos parentais do Híbrido de Timor (HDT) e de outros híbridos interespecíficos como o "Icatu". Várias plantas do HDT possuem pelo menos os genes $\mathrm{S}_{\mathrm{H}} 5$ a $\mathrm{S}_{\mathrm{H}} 9$ (BetTencourt et al., 1992). Tem sido confirmada a existência de outros genes maiores em derivados do HDT (RodRIGUEs-JunIOR et al., 2000).

A 'IAPAR 59' foi originada da hibridação entre “Villa Sarchi CIFC 971/10" e "HDT CIFC 832/2" e possui pelo menos cinco genes de resistência à ferrugem (genes $S_{H}$ ). A 'IPR 107' foi originada do cruzamento entre 'IAPAR 59' (resistente) e 'Mundo Novo IAC 376-4' (suscetível) e a 'IPR 99' é derivada do mesmo cruzamento que originou a 'IAPAR 59'. Nas várias gerações de autofecundação para a obtenção das cultivares IPR 99 e IPR 107 ocorreram segregações para os genes de resistência e, atualmente, muitas progênies possuem alta freqüência de plantas suscetíveis. É provável que em algumas progênies das cultivares IPR 99 e IPR 107 existam os mesmos fatores de resistência da 'IAPAR 59' ou do "HDT CIFC 832/2", os quais vêm se mantendo resistentes por muitos anos.

O desenvolvimento de cultivares com vários genes $S_{H}$ e com outros genes maiores ou menores é de extrema importância para obter uma resistência durável. A porcentagem de plantas com esporulação da ferrugem (PEF) tem sido um parâmetro utilizado no programa de melhoramento genético de café do IAPAR para identificar cafeeiros com mais genes $S_{H}$ não quebrados pela ferrugem (SERA et al., 2005, 2007). No IAPAR, a frequência de PEF tem sido analisada em progênies derivadas da autofecundação e de cruzamentos testes (genótipo a ser testado $\mathrm{x}$ genótipo suscetível).

Os objetivos deste estudo foram: a) Identificar progênies das cultivares IPR 99 e IPR 107 com mais genes de resistência não quebrados pela ferrugem; b) Identificar progênies com resistência incompleta; c) Verificar se cruzamentos testes são eficientes na identificação de cafeeiros portadores de mais genes de resistência à ferrugem.

Quatro ensaios de campo, denominados E1, E2, E3 e E4, respectivamente, foram instalados em março de 2001, março de 1999, março de 2003 e setembro de 2003, no espaçamento $2,5 \mathrm{~m} \times 0,5 \mathrm{~m}$ em Londrina $\left(23^{\circ} 22^{\prime} \mathrm{S}\right.$, $\left.51^{\circ} 10^{\prime} \mathrm{W}\right)$. Neste local, a altitude é $585 \mathrm{~m}$, a precipitação pluvial média anual é $1610 \mathrm{~mm}$, a temperatura média anual é de $20,8{ }^{\circ} \mathrm{C}$ e a umidade relativa do ar, de $71 \%$. Nos anos de avaliação da resistência dos cafeeiros não foi realizado o controle químico para ferrugem.

A avaliação da resistência, em condições de campo, foi realizada para a população local de raças de ferrugem presentes na estação experimental do IAPAR. No ensaio E1 foi realizada uma avaliação em julho de 2004 (40 meses após o plantio) e outra em julho de 2007 (76 meses após o plantio). No ensaio E2, a avaliação foi em julho de 2004 (64 meses após o plantio). A avaliação no ensaio E3 foi realizada em julho de 2005 (28 meses após o plantio) e outra em agosto de 2007 (54 meses após o plantio). A avaliação no ensaio $\mathrm{E} 4$ foi em julho de 2007 (47 meses após o plantio).

No ensaio E1, duas progênies $\mathrm{F}_{4}$ da 'IPR 99' (C1P2 e C3P2) foram avaliadas por meio de cruzamentos testes, os quais consistem em cruzar um genótipo a ser testado com um genótipo suscetível. Os cruzamentos testes realizados foram: dois da hibridação ("Coffea arabica da Etiópia portador do gene $S_{H} 1$ " $x$ "Catuaí") x progênie $\mathrm{F}_{4}$ da 'IPR 99-C1P2' e três da hibridação ("C. arabica da Etiópia portador do gene $S_{\mathrm{H}} 1$ " $\mathrm{x}$ "Catuaí") x progênie $\mathrm{F}_{4}$ da 'IPR 99-C3P2'. O parental suscetível usado nesses cruzamentos testes foi o "C. arabica da Etiópia portador do gene $S_{H} 1$ " x "Catuaí". Os híbridos usados como padrões suscetíveis foram derivados do cruzamento entre dois parentais suscetíveis, sendo um derivado do cruzamento de ("C. arabica da Etiópia portador do gene $S_{H} 1$ " $x$ "Catuaí") com 'Icatu IAC 3282' e o outro de 'Catuaí Vermelho IAC 81' com “Catuaí Semperflorens".

No E2 foram avaliadas cinco progênies $F_{5}$ da 'IPR 99' (C1P2, C1P3, C3P1, C3P2 e C6P2). As cultivares IAPAR 59 ("Sarchimor") e Catuaí Vermelho IAC 81 foram usadas como padrões de resistência completa e suscetibilidade respectivamente.

No E3 foram avaliados 23 cruzamentos testes (suscetível x progênies $\mathrm{F}_{3}$ de 'IPR 107'), sendo nove com a 'Catuaí Vermelho IAC-81' e 14 com a 'Mundo Novo IAC 376-4', ambas suscetíveis à ferrugem. 'IAPAR 59' foi usada como padrão resistente e 'Bourbon Vermelho', 'Catuaí Vermelho IAC 81' e 'Icatu IAC 3282' como padrões suscetíveis.

No E4 foram avaliadas 11 progênies $\mathrm{F}_{4}$ da cultivar IPR 107. Dessas progênies, nove foram provenientes das 
progênies $\mathrm{F}_{3} 13-6,14-1,14-3,14-5,17-2,17-5,20-1,25-2$ e 25-10, utilizadas em cruzamentos testes do ensaio E3. 'IAPAR 59' foi o padrão resistente e 'Catuaí Vermelho IAC 81' o padrão suscetível.

A avaliação da intensidade de ferrugem (IF) foi feita com base em uma escala de notas de 1 a 5, sendo: nota 1 = plantas sem lesões cloróticas nas folhas; nota 2 = número de lesões por folha, em média, entre 1 e 4, sem esporulação; nota 3 = entre 1 e 10 lesões com esporos por folha e frequência de folhas com esporulação entre $1 \%$ e $10 \%$; nota 4 = entre 11 e 20 lesões com esporos por folha e frequência de folhas com esporulação entre $11 \%$ e 35\%; nota 5 = mais de 20 lesões com esporos por folha e mais de $35 \%$ das folhas com esporulação. As notas foram atribuídas para plantas individuais. A avaliação foi desde o terço inferior até o terço superior do cafeeiro.

Plantas com notas 1 e 2 de IF foram consideradas com resistência completa. Plantas com esporulação da ferrugem (PEF) foram aquelas com notas 3, 4 e 5.
A porcentagem de PEF e as notas médias de IF foram usadas como parâmetros para: a) Identificar progênies das cultivares IPR 99 e IPR 107 com mais genes de resistência não quebrados pela ferrugem; b) Identificar progênies com resistência incompleta; c) Verificar a eficiência dos cruzamentos testes. Cafeeiros com notas 1 ou 2 em ano de avaliação, porém que tiveram notas 3, 4 ou 5 em outro ano, não foram considerados com resistência completa. Esses cafeeiros com notas 3, 4 ou 5, em pelo menos uma das avaliações, foram consideradas PEF. Foram considerados cafeeiros com resistência parcial aqueles com $90 \%$ a $100 \%$ de PEF e com notas médias de IF entre 2,00 e 4,00. O número de plantas avaliadas de cada tratamento está apresentado nas tabelas 1, 2, 3 e 4 .

Ocorreu a esporulação da ferrugem em vários cafeeiros dos cruzamentos testes com a progênie $F_{4}$ de 'IPR 99-C1P2'. As frequências de PEF nos dois cruzamentos testes com a 'IPR 99-C1P2' foram 100,00\% e $88,24 \%$. Por outro lado, as frequências de PEF dos

Tabela 1. Notas médias da intensidade de ferrugem avaliada em julho de 2004 e em julho de 2007 (IF04, IF07), porcentagem de plantas com esporulação da ferrugem em 2004 e em 2007 (\% PEF 04/ 07) e número de plantas avaliadas (n. ${ }^{\circ}$ ) de cruzamentos testes com progênies $\mathrm{F}_{4}$ da 'IPR 99' avaliadas para a população local de raças, em condições de campo (Ensaio E1)

\begin{tabular}{|c|c|c|c|c|}
\hline Cruzamentos testes $\left({ }^{1}\right)$ & IF04 $\left({ }^{2}\right)$ & IF07 $\left({ }^{2}\right)$ & $\%$ PEF 04/ $07\left({ }^{3}\right)$ & n. ${ }^{\circ}$ \\
\hline (“Et. $S_{H} 1$ " x "Catuaî") x $F_{4}$ de IPR 99-C3P2 & 1,00 & 1,00 & 0,0 & 2 \\
\hline (“Et. $S_{H} 1$ " x “Catuaî") x $F_{4}$ de IPR 99-C3P2 & 1,75 & 1,19 & 18,75 & 16 \\
\hline (“Et. $S_{H} 1$ " x “Catuaî") x $F_{4}$ de IPR 99-C3P2 & 1,88 & 1,82 & 29,41 & 17 \\
\hline (“Et. $S_{H} 1$ " x “Catuaî") x $F_{4}$ de IPR 99-C1P2 & 2,76 & 3,29 & 88,24 & 17 \\
\hline (“Et. $S_{H} 1$ " x “Catuaî”) x $F_{4}$ de IPR 99-C1P2 & 3,75 & 4,94 & 100,0 & 16 \\
\hline * ‘Catuaî́” x "Catuaí Semperflorens" & 4,50 & 5,00 & 100,0 & 12 \\
\hline * (“Et. $\mathrm{S}_{\mathrm{H}} 1$ ” x “Catuaî”) x ‘Icatu IAC 3282' & 4,82 & 4,88 & 97,06 & 17 \\
\hline
\end{tabular}

(1) Et. $S_{\mathrm{H}} 1=\left({ }^{\text {“C }}\right.$. arabica da Etiópia portador do gene $\mathrm{S}_{\mathrm{H}} 1$ ” $\mathrm{x}$ "Catuaí” $)$; 'Catuaí' = 'Catuaí Vermelho IAC 81'. * Padrões suscetíveis.

$\left({ }^{2}\right)$ Escala de notas de 1 a 5 de IF, sendo nota 5 plantas com mais IF. $\left({ }^{3}\right)$ Notas 1 e 2 = plantas com resistência completa; notas 3 , 4 e $5=$ PEF.

Tabela 2. Notas médias da intensidade de ferrugem (IF), porcentagem de plantas com esporulação da ferrugem (\% PEF) e número de plantas avaliadas $\left(n .^{\circ}\right)$ de progênies $\mathrm{F}_{5}$ da 'IPR $99^{\prime}$ avaliadas para a resistência à população local de raças em condições de campo, em julho de 2004 (Ensaio E2)

\begin{tabular}{lccc}
\hline Progênies F $_{5}$ & IF $\left({ }^{1}\right)$ & \% PEF $\left(^{2}\right)$ & $\mathrm{n}^{\circ}$ \\
\hline IPR 99 - C1P2 & 2,79 & 57,14 & 28 \\
IPR 99 - C1P3 & 1,82 & 7,14 & 28 \\
IPR 99 - C3P1 & 1,63 & 8,33 & 24 \\
IPR 99 - C3P2 & 2,04 & 11,11 & 27 \\
IPR 99 - C6P2 & 1,48 & 0,00 & 27 \\
'Catuaí Vermelho IAC 81' (padrão suscetível) & 4,91 & 100,00 & 22 \\
'IAPAR 59' (padrão resistente) & 1,65 & 0,00 & 20 \\
\hline
\end{tabular}

$\left({ }^{1}\right)$ Escala de notas de 1 a 5 de IF, sendo nota 5 plantas com mais IF. $\left({ }^{2}\right)$ Notas 1 e 2 = plantas com resistência completa; notas 3 , 4 e $5=$ PEF. 
Tabela 3. Intensidade média da ferrugem avaliada em julho de 2005 (IF 05) e agosto de 2007 (IF 07), porcentagem de plantas com esporulação da ferrugem nos anos de 2005 e 2007 (\% PEF 05/ 07) e número de plantas avaliadas (n..$\left.^{\circ}\right)$ para a resistência à população local de raças em cruzamentos testes realizados com progênies $\mathrm{F}_{3}$ da cultivar IPR 107 (Ensaio E3)

\begin{tabular}{|c|c|c|c|c|}
\hline Cruzamentos testes $\left({ }^{1}\right)$ & IF 05 & IF 07 & $\%$ PEF 05/ $07\left({ }^{2}\right)$ & n. ${ }^{\circ}$ \\
\hline 'IAPAR 59’ & 1,000 & 1,160 & 4,00 & 25 \\
\hline Catuaí V. x progênie $29-8$ & 1,000 & 1,000 & 0,00 & 5 \\
\hline Catuaí V. x progênie $14-3 *$ & 1,200 & 1,300 & 10,00 & 10 \\
\hline M. Novo x progênie 17-1 & 1,380 & 1,680 & 28,00 & 50 \\
\hline M. Novo x progênie $17-2 *$ & 1,592 & 1,388 & 28,57 & 49 \\
\hline Catuaí V. x progênie $28-8$ & 1,800 & 1,600 & 40,00 & 5 \\
\hline M. Novo x progênie $14-10$ & 2,467 & 2,400 & 53,34 & 15 \\
\hline M. Novo x progênie 13-9 & 2,533 & 2,000 & 60,00 & 30 \\
\hline Catuaí V. x progênie $14-5 *$ & 2,500 & 2,700 & 60,00 & 10 \\
\hline M. Novo x progênie $17-5 *$ & 2,440 & 1,980 & 64,00 & 50 \\
\hline M. Novo x progênie $13-6 *$ & 2,786 & 1,357 & 64,29 & 14 \\
\hline M. Novo x progênie 18-7 & 2,840 & 2,600 & 68,00 & 25 \\
\hline M. Novo x progênie 15-9 & 2,833 & 2,533 & 80,00 & 30 \\
\hline M. Novo x progênie $25-2 *$ & 2,582 & 3,255 & 90,91 & 55 \\
\hline Catuaí V. x progênie $14-1 *$ & 2,067 & 2,867 & 93,33 & 15 \\
\hline M. Novo x progênie 21-1 & 2,980 & 2,500 & 94,00 & 50 \\
\hline Catuaí V. x progênie $28-10$ & 2,867 & 2,667 & 100,00 & 15 \\
\hline M. Novo x progênie 24-5 & 2,950 & 3,050 & 100,00 & 20 \\
\hline Catuaí V. x progênie 23-6 & 3,000 & 3,200 & 100,00 & 5 \\
\hline M. Novo x progênie $20-1 *$ & 3,120 & 3,320 & 100,00 & 25 \\
\hline M. Novo x progênie 26-6 & 3,441 & 3,678 & 100,00 & 59 \\
\hline M. Novo x progênie 23-5 & 3,200 & 4,080 & 100,00 & 25 \\
\hline Catuaí V. x progênie 27-5 & 4,000 & 4,600 & 100,00 & 5 \\
\hline Catuaí V. x progênie $25-10 *$ & 4,400 & 4,500 & 100,00 & 10 \\
\hline 'Icatu IAC 3282' & 5,000 & 4,440 & 100,00 & 25 \\
\hline Catuaí V. & 4,933 & 4,640 & 100,00 & 25 \\
\hline ‘Bourbon Vermelho’' & 5,000 & 4,720 & 100,00 & 25 \\
\hline
\end{tabular}

* Progênies da cultivar IPR 107 avançadas para a geração $\mathrm{F}_{4}$.

(1) M. Novo = 'Mundo Novo IAC 376-4'; Catuaí V. = 'Catuaí Vermelho IAC-81'.

( $\left.{ }^{2}\right)$ Notas 1 e 2 = plantas com resistência completa; notas 3, 4 e $5=$ PEF.

três cruzamentos testes com a 'IPR 99-C3P2' foram $0 \%$, $18,75 \%$ e 29,41\%. Esses valores indicam que na progênie C3P2 da 'IPR 99' houve mais genes de resistência não quebrados pela população local de raças (Tabela 1).

Na progênie $F_{5}$ IPR 99-C1P2 foram observadas $57,14 \%$ de PEF, enquanto na progênie $\mathrm{F}_{5}$ IPR 99-C3P2, apenas $11,11 \%$ de PEF (Tabela 2). Portanto, confirmase que na progênie IPR 99-C3P2 houve mais genes de resistência não quebrados pela ferrugem ou mais desses genes estão em condição homozigótica quando comparado com a progênie C1P2.

Não foram realizados cruzamentos testes para as progênies $\mathrm{C} 1 \mathrm{P} 3, \mathrm{C} 3 \mathrm{P} 1$ eC6P2. Entretanto, essas progênies também tiveram mais genes não quebrados, pois a porcentagem de PEF foi mais baixa nessas progênies $\mathrm{F}_{5}$, em comparação com a progênie C1P2 e o padrão suscetível 'Catuaí Vermelho IAC 81'. Na progênie C6P2, não se observou nenhuma $\mathrm{PEF}$, do mesmo modo que 
Tabela 4. Nota média da intensidade de ferrugem (IF), porcentagem de plantas com esporulação da ferrugem (\% PEF) e número de plantas avaliadas $\left(\right.$ n. $\left.^{\circ}\right)$ para a resistência à população local de raças em progênies $\mathrm{F}_{4}$ da 'IPR 107' (Ensaio E4)

\begin{tabular}{llll}
\hline Progênies F da 'IPR 107' $_{4}$ & IF & \% PEF $\left(^{1}\right)$ & 23 \\
\hline $17-2 *$ & 1,087 & 10,00 & 10 \\
'IAPAR 59' (padrão resistente) & 1,200 & 27,08 & 48 \\
$14-1 *$ & 1,833 & 29,63 & 54 \\
$14-3 *$ & 1,944 & 60,00 & 25 \\
$17-5 *$ & 2,680 & 62,50 & 40 \\
$14-5 *$ & 2,525 & 67,92 & 53 \\
$25-2 *$ & 2,849 & 72,09 & 43 \\
$13-6 *$ & 2,844 & 93,55 & 31 \\
$20-1 *$ & 4,355 & 98,31 & 59 \\
$25-10 *$ & 4,593 & 100,00 & 28 \\
$18-10$ & 4,607 & 100,00 & 14 \\
$18-2$ & 4,786 & 100,00 & 9 \\
'Catuaí Vermelho IAC 81' (padrão suscetível)
\end{tabular}

* Foram realizados cruzamentos testes para essas progênies. ${ }^{(1)}$ Notas 1 e 2 = plantas com resistência completa; notas 3 , 4 e $5=$ PEF.

no padrão resistente 'IAPAR 59'. Pelas notas médias de IF das progênies $F_{5}$ C1P3, C3P1, C3P2 e C6P2 é possível verificar que o nível de resistência dessas plantas é similar ao da 'IAPAR 59' (Tabela 2).

A média da porcentagem de PEF dos dois cruzamentos testes com IPR 99-C1P2 foi similar ao dos padrões suscetíveis (Tabela 1). Entretanto, as notas médias de SF desses dois cruzamentos foram mais baixas que as médias de SF dos padrões suscetíveis, indicando ser a progênie C1P2 de resistência incompleta ou parcial. A média da porcentagem de PEF dos dois cruzamentes testes com a C1P2 em 2004 e 2007 foi de $93,94 \%$, enquanto a média de IF foi de 3,67. As médias de IF dos padrões suscetíveis nos dois anos de avaliação foram 4,75 e 4,85 respectivamente, para ("C. arabica da Etiópia $S_{\mathrm{H}} 1$ ” x “Catuaí") x 'Icatu IAC 3282' e 'Catuaí Vermelho IAC 81' x “Catuaí Semperflorens”. Assim, se a resistência de outras progênies da 'IPR 99' for quebrada, provavelmente, terão ainda resistência incompleta para evitar que repentinamente se torne uma cultivar completamente suscetível.

A resistência incompleta observada na progênie C1P2 pode ser devido à resistência residual de alguns genes do HDT CIFC 832-2 quebrados pela ferrugem. Em cafeeiros com os genes $S_{H} 1, S_{H} 3$ e $S_{H} 4$ (ESKES, 1989) e em derivados do "HDT" como a cultivar Colômbia (AlvarADO, 2005) também foi observada resistência residual após a quebra. A resistência incompleta também pode ter ocorrido devido à ação de genes menores, do mesmo modo que ocorreu em plantas do "Icatu" e "HDT" em trabalho realizado por EsKes et al. (1990). A resistência parcial em 'IPR 99' também poderia ser explicada pelo início tardio da infecção pela ferrugem, pois é possível que a população predominante seja da raça II (v5), sendo esta a que ocorre com mais frequência no Brasil, conforme ZAMBOLIM et al. (2005).

Como já era esperado, em vários cruzamentos testes com as progênies da 'IPR 107' foi observada alta porcentagem de PEF, pois a cultivar Mundo Novo IAC 376-4' (suscetível) é um dos parentais desta cultivar. Os cruzamentos testes com as progênies $\mathrm{F}_{3}$ 29-8, 14-3, 17-1 e 17-2 foram os que tiveram as mais baixas porcentagens de PEF. Nas duas primeiras houve porcentagens altas de plantas com resistência completa, semelhante ao da cultivar IAPAR 59 (padrão resistente). Nos demais cruzamentos testes, utilizando outras progênies $\mathrm{F}_{3}$ da 'IPR 107', foram observadas altas porcentagens de PEF (Tabela 3).

A progênie $\mathrm{F}_{4}$ 17-2 da 'IPR 107' foi a única com $100 \%$ das plantas com resistência completa. As progênies $\mathrm{F}_{4}$ 14-1 e 14-3 com frequências relativamente baixas de PEF, respectivamente, 27,08\% e 29,63\%, foram, porém, superiores em comparação com o padrão 'IAPAR 59', com $10 \%$ de PEF (Tabela 4).

A frequência de PEF no cruzamento 'Catuaí Vermelho IAC $81^{\prime}$ x progênie $\mathrm{F}_{3}$ 14-3 foi $10,00 \%$ e, portanto, baixa em comparação com outros cruzamentos como no caso do 'Catuaí Vermelho 
IAC 81' x progênie $F_{3} 14-1$ com 93,33\% (Tabela 3). Entretanto, nas progênies $F_{4}$ 14-3 e 14-1 notaramse porcentagem de PEF similar (Tabela 4). Esse fato indica que na progênie $\mathrm{F}_{3} 14-3$ houve poucos genes de resistência não quebrados pela ferrugem, do mesmo modo que a progênie 14-1. A baixa frequência de PEF no cruzamento teste com a progênie $F_{3} 14-3$ pode ter ocorrido em vista da pouca quantidade de plantas avaliadas derivadas do cruzamento teste $(n=10)$ (Tabela 3). Para o cruzamento teste com a progênie 29-8 todas as plantas proporcionaram resistência completa, entretanto, também poucas plantas $(n=5)$ foram avaliadas (Tabela 3). Portanto, novas avaliações deverão ser realizadas na progênie 29-8.

Para a progênie 17-2, foi observada baixa frequência de PEF tanto no cruzamento teste quanto na geração $F_{4}$. A progênie 17-1 não foi avançada para a geração $\mathrm{F}_{4^{\prime}}$ entretanto, no cruzamento teste a quantidade de PEF foi similar ao da 17-2, mesmo sendo avaliadas muitas plantas $(n=50)$.

Pelas notas médias de IF, constata-se que o nível de resistência das progênies 17-1, 17-2 e 29-8 é similar ao da 'IAPAR 59' (Tabela 3). Provavelmente, essas progênies tiveram os mesmos genes de resistência da 'IAPAR 59', pois esta é um dos parentais da 'IPR 107'. As progênies $17-1$ e 29-8 serão avançadas para geração $F_{4^{\prime}}$ enquanto a 17-2 será avançada para a geração $\mathrm{F}_{5}$.

Provavelmente, as progênies da 'IPR 107' com muitas PEF não são portadoras de algum gene $S_{H}$ ou de outros provenientes da 'IAPAR 59' ou do "HDT CIFC 832-2". Entretanto, foi observada resistência incompleta em quase todas as progênies com $90 \%$ a $100 \%$ de PEF, pois suas notas médias de IF foram bem inferiores em comparação com a média dos padrões suscetíveis 'Bourbon Vermelho', 'Catuaí Vermelho IAC 81' e 'Icatu IAC 3282' (Tabela 3). Dez progênies $F_{3}$ tiveram resistência incompleta à população local de raças de ferrugem. As explicações sobre a resistência residual e durabilidade da resistência dessas progênies da 'IPR $107^{\prime}$ podem ser as mesmas descritas anteriormente para a cultivar IPR 99, pois ambas possuem genes do HDT CIFC 832-2.

As porcentagens de PEF nos cruzamentos testes com as progênies $\mathrm{F}_{4} \mathrm{C} 1 \mathrm{P} 2$ e C3P2 da 'IPR 99' foram mais altas do que nas respectivas progênies $F_{5}$ derivadas da autofecundação. Enquanto na progênie $\mathrm{F}_{5} \mathrm{C} 3 \mathrm{P} 2 \mathrm{a}$ frequência de PEF foi $11,11 \%$, nos cruzamentos testes com a progênie $\mathrm{F}_{4} \mathrm{C} 3 \mathrm{P} 2$ a frequência média foi de $15,79 \%$. Do mesmo modo na progênie $\mathrm{F}_{5} \mathrm{C} 1 \mathrm{P} 2$ a frequência de PEF foi de $57,14 \%$ e nos cruzamentos testes com a progênie $\mathrm{F}_{4}$ C1P2 a freqüência média foi de 95,35\%.

Para as progênies da cultivar IPR 107, na maioria dos cruzamentos testes, foi observada porcentagem mais alta de PEF do que nas progênies $F_{4}$ provenientes da autofecundação. Isto pôde ser mais bem observado para os cruzamentos testes com as progênies 14-1, 17-2 e 25-2 (Tabela 3). Para as progênies 13-6, 14-3 e 14-5 ocorreram mais PEF nas progênies derivadas da autofecundação (Tabela 4), provavelmente, porque foram avaliadas poucas plantas $(\mathrm{n}<15)$ nos cruzamentos testes (Tabela 3). Portanto, para identificar cafeeiros com mais genes de resistência por meio dos cruzamentos testes, muitas plantas deverão ser avaliadas para que o resultado seja mais confiável.

Para várias progênies das cultivares IPR 99 e IPR 107 não foi ampla a diferença entre a porcentagem de PEF das progênies derivadas do cruzamento teste em comparação com as derivadas da autofecundação. Como um exemplo no cruzamento teste com a progênie $\mathrm{F}_{3} 17-5$ de 'IPR 107', a porcentagem de PEF foi de 64\% (Tabela 3), enquanto a progênie $\mathrm{F}_{4} 17-5$ derivada da autofecundação de $60 \%$ (Tabela 4). É provável que o uso de cruzamentos testes seria mais útil para situações em que cafeeiros tivessem vários genes maiores em condição heterozigótica e fossem inoculados com raças portadoras de poucos fatores de virulência. Um exemplo deste caso seria o uso dos cruzamentos testes em progênies $\mathrm{F}_{2}$ derivadas do cruzamento entre "HDT CIFC 832/2" $\left(\mathrm{S}_{\mathrm{H}} 5, \mathrm{~S}_{\mathrm{H}} 6, \mathrm{~S}_{\mathrm{H}} 7, \mathrm{~S}_{\mathrm{H}} 8\right.$, $\mathrm{S}_{\mathrm{H}} 9, \mathrm{~S}_{\mathrm{H}}$ ?) e 'Mundo Novo' $\left(\mathrm{S}_{\mathrm{H}} 5\right)$, submetidas à inoculação com a raça II (v5). Cruzamentos testes são mais difíceis de serem feitos do que a autofecundação, que é natural em Coffea arabica. Porém, a realização dos cruzamentos testes em progênies $\mathrm{F}_{2}$ e $\mathrm{F}_{3}$ é muito útil, pois o tamanho da população de plantas não diminui somente nas gerações seguintes, mas também nas outras gerações. Realizando os cruzamentos testes na $\mathrm{F}_{2}$ é diminuído o número de progênies $\mathrm{F}_{3}$ que deverão ser avaliadas para a resistência à ferrugem, consequentemente, também é diminuído o número de progênies $\mathrm{F}_{4^{\prime}} \mathrm{F}_{5^{\prime}} \mathrm{F}_{6}$ eassim por diante, reduzindo bastante o número final de plantas avaliadas para se obter uma cultivar com resistência à ferrugem.

Com base na porcentagem de PEF dos cafeeiros derivados da autofecundação e dos cruzamentos testes é possível identificar cafeeiros com mais genes $S_{H}$ não quebrados pela ferrugem (SERA et al., 2005, 2007). Este método é muito útil e simples para uma seleção preliminar de cafeeiros com mais genes de resistência à ferrugem, apesar da menor precisão quando comparado com avaliações por meio de inoculações artificiais de raças com genes de virulência conhecidos. Neste trabalho, quase todas as progênies da 'IPR 107' e uma progênie da 'IPR 99' foram descartadas pela sua alta porcentagem de PEF. Assim, somente as progênies com baixa porcentagem de PEF serão analisadas com mais precisão, o que diminui os custos e o tempo para o melhoramento genético do cafeeiro. 


\section{AGRADECIMENTOS}

Os autores agradecem ao Instituto Agronômico do Paraná (IAPAR) e ao Consórcio Pesquisa Café por apoiarem financeiramente este trabalho; ao $\mathrm{CNPq}$, à CAPES e à Universidade Estadual de Londrina pelas bolsas de doutorado concedidas.

\section{REFERÊNCIAS}

ALVARADO, G.A. Evolution of Hemileia vastatrix virulence in Colômbia. In: ZAMBOLIM, L.; ZAMBOLIM, E. M.; VÁRZEA, V. M. P. (Eds.). Durable Resistance to Coffee Leaf Rust. Viçosa: UFV, 2005. p.99-116.

BETTENCOURT, A.J. Melhoramento genético do cafeeiro: transferência de factores de resistência à Hemileia vastatrix Berk. \& Br. para as principais cultivares de Coffea arabica L. Lisboa: ULTRAMAR/CIFC, 1981.93 p.

BETTENCOURT, A.J.; LOPES, J.; PALMA, S. Fatores genéticos que condicionam a resistência às raças de Hemileia vastatrix Berk. et Br. dos clones-tipo dos grupos 1, 2 e 3 de derivados de Híbrido de Timor. Brotéria Genética, v.13, p.185-194, 1992.

ESKES, A.B. Resistance. In: KUSHALAPPA, A.C.; ESKES, A. B. (Ed.). Coffee rust: epidemiology, resistance and management. Boca Raton: CRC Press, 1989. p.171-292.

ESKES, A.B.; HOOGSTRATEN, J.G.J.; TOMA-BRAGHINI, M.; CARVALHO, A. Race-specificity and inheritance of incomplete resistance coffee leaf rust in some Icatu coffee progenies and derivatives of Hibrido de Timor. Euphytica, v.47, p.11-19, 1990.
RODRIGUES-JUNIOR, C.J.; BETTENCOURT A.J.; RIJO, L. Races of the pathogen and resistance to coffee rust. Annual Review of Phytopathology, v.13, p.49-70, 1975.

RODRIGUES-JUNIOR, C.J.; VÁRZEA, V.M.P.; SILVA, M.C.; GUERRA-GUIMARÃES, L.; ROCHETA, M.; MARQUES, D.V. Recent advances on coffee leaf rust. In: INTERNATIONAL SCIENTIFIC SYMPOSIUM ON COFFEE, 2000, Bangalore. Proceedings... Bangalore, India: Central Coffee Research Institute, 2000. p.179-193.

SERA, G.H.; SERA, T.; ITO, D.S.; AZEVEDO, J.A.; MATA, J.S.; DOI, D.S.; RIBEIRO-FILHO, C. Selection for durable resistance to leaf rust using test-crosses on IAPAR-59 and Tupi IAC 166933 cultivars of Coffea arabica. Brazilian Archives of Biology and Technology, v.50, p.565-570, 2007.

SERA, T.; SERA, G.H.; ITO, D.S.; DOI, D.S. Coffee breeding for durable resistance to leaf rust disease at Instituto Agronômico do Paraná. In: ZAMBOLIM, L.; ZAMBOLIM, E. M.; VÁRZEA, V. M. P. (Ed.). Durable Resistance to Coffee Leaf Rust. Viçosa: UFV, 2005. p. 187-214.

VARZEA, V.M.P.; MARQUES, D.V. Population variability of Hemileia vastatrix vs. coffee durable resistance. In: ZAMBOLIM, L.; ZAMBOLIM, E.M.; VÁRZEA, V.M.P. (Ed.). Durable Resistance to Coffee Leaf Rust. Viçosa: UFV, 2005. p.53-74.

ZAMBOLIM, L.; ZAMBOLIM, E.M.; VALE, F.X.R. do; PEREIRA, A.A.; SAKYAMA, N. S.; CAIXETA, E.T. Physiological races of Hemileia vastatrix Berk. et Br. in Brazil - Physiological variability, current situation and future prospects. In: ZAMBOLIM, L.; ZAMBOLIM, E.M.; VÁRZEA, V.M.P. (Ed.). Durable Resistance to Coffee Leaf Rust. Viçosa: UFV, 2005. p.75-98. 